\title{
"Domestication" of renewable energy from a Polish perspective
}

\author{
A. Szubryt-Obrycka \\ Department of Architecture and Urban Planning, \\ West Pomeranian University of Technology, Poland
}

\begin{abstract}
Research conducted by the author aims to disseminate the possibilities of applying renewable energy solutions in the housing industry, in particular - photovoltaic systems in single-family housing. The use of this technology is greatly facilitated legally, however, insufficient public awareness on this topic is still a significant barrier. It is possible to develop appropriate schemes and techniques - and the methodologies of their implementation - on a stage of the design process, in order to introduce modular RES solutions to the European residential construction market. The author attempts to determine the economic threshold of accessibility of those solutions, specifically the amount of additional costs that the investor is willing to accept, and, above all, the design possibilities with an emphasis on aesthetic solutions that are fully accepted by investors.

Keywords: sustainable architecture, single-family housing, renewable energy sources, photovoltaics.
\end{abstract}

\section{Introduction}

The idea of the theory of sustainable development in architectural design implies a balance of environmental, social, economic and political aspects. Therefore, functioning of the theory in practice must be based on all those issues, merging them appropriately with one another. Such an idea is also supported by Andrzej Baranowski [1], who refers to the postulate of

the balance between limited resources and self-regulating and immunological potential of the environment and irresponsibly growing needs of the consumer society, the balance between the natural environment and the socio-cultural one. 
Compliance with the concept of sustainable development is becoming more and more noticeable in the newly designed public buildings, especially in the office centers and industrial facilities.

Poland is obliged to ensure that $15 \%$ of its total energy production is generated from renewable energy sources (RES) until 2020. Considering the experiences of other European countries in this matter to meet those requirements, the RES industry must constantly develop the increasing amount of constructed renewable energy production plants. However, said development is not limited to large installations and projects. An equally important element is to promote the possibilities of applying RES solutions as micro-installations, among others in the construction industry.

At the moment, the RES solutions are increasingly used by the Polish commercial construction market - in offices and industrial and public buildings. This applies particularly to the production of electricity by photovoltaic installations, encouraged from Polish legal regulations and economic and technological accessibility of photovoltaics.

In the author's opinion however, great emphasis should be put on promoting the possibilities of applying the RES solutions in residential construction, particularly in single-family housing. The use of this technology is greatly facilitated legally. However, insufficient public awareness on this topic is still a significant barrier. It is possible to develop appropriate schemes and techniques and the methodologies of their implementation - on a stage of the design process, in order to introduce modular RES solutions to the European residential construction market. Therefore, the author carries out in this paper a survey among the community in order to identify the current level of the potential investors' knowledge in the subject of photovoltaic systems, the possibilities of incurring additional financial costs associated with applying the systems, and most of all the preferences regarding the aesthetic aspects of PV solutions and their application in particular building structures.

\section{Photovoltaics}

Photovoltaic systems may be determined as the main type of renewable energy source exploited in the single-family housing and on their application bases her research. In the author's opinion, it is photovoltaics and photovoltaic glass in particular, that holds the potential to be the RES commonly used in residential construction market.

Constant development and conducted research on the efficiency improvement and production capabilities, such as Spectrolab's research [4], already offer a wide range of possibilities for the use of photovoltaics. However, it is necessary to propagate the topic not only among the communities - the potential investors but also among designers.

At the moment, the photovoltaic (PV) glass is widely used by the commercial construction market - in office, industrial and public buildings - and it succeeds as an alternative solution for glass facades. As Dou, Zhu and their team prove in their studies [7], new technologies allow for the production of the PV glass with 


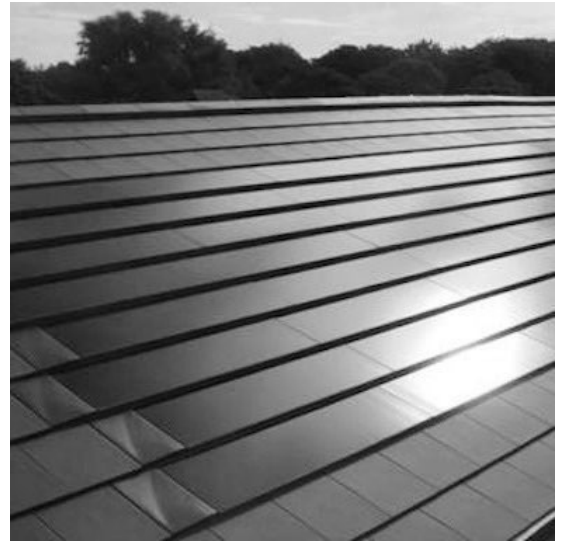

Figure 1: An example of application of currently available photovoltaic roof tiles [2].

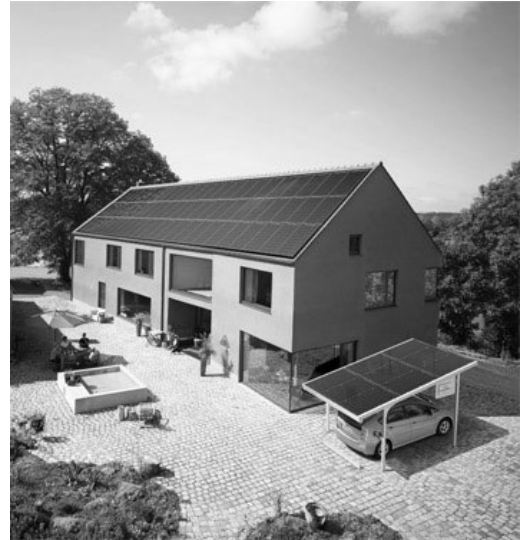

Figure 2: Visualization of the use of a traditional PV on a roof; dominant in the building's architectural design [3].

even higher transparency, which significantly improves the comfort and aesthetics of the interiors. Commercially available batteries (e.g. Tesla's Powerwall) with capabilities to store the generated energy help to solve the problem of using the PV glass in facilities that are barely occupied and used during the day. New production lines give a wide range of possibilities in terms of dimensions, thickness or colors of the glass, which significantly increases the potential use of PV glass in smaller objects, like single-family housing. The barrier at the moment is the social acceptance.

Qualitative research, conducted by the author among the Polish community, is intended to show the current state of knowledge of the potential investors in the subject of available solutions, project opportunities and regulations and - above all - to determine the architectural and economic accessibility of these solutions.

\section{Thematic block 1}

The study was conducted using a questionnaire, which consisted of four thematic blocks. In the first block the author estimates current level of the respondents' awareness in the topic of photovoltaic systems, in particular types of photovoltaic systems that can be used in single-family housing, technical possibilities of commonly applied solutions, the legal status of the rules concerning the sale of surplus of produced energy and the types of support and funding that can be obtained from the state.

The results' analysis indicates a very poor knowledge of legal possibilities of the use of photovoltaic systems. $38.3 \%$ of respondents indicated a lack of that knowledge, the same percentage rated their knowledge as poor. As for the 
possibilities of obtaining funding from the state, $42.6 \%$ of respondents reported a lack of knowledge and $36.2 \%$ considered their knowledge as poor.

The degree of knowledge of the technical possibilities of photovoltaic systems' application looks a bit better. $38.3 \%$ of the respondents ranked their knowledge as average, but the percentage of poor knowledge and the lack of it is $25.5 \%$ in each case. Investors turn out to be the most knowledgeable in the subject of types of photovoltaic systems $-38.3 \%$ of respondents claim to have average knowledge. Still, $19.1 \%$ of respondents indicated a lack of any knowledge in this field.

Interestingly, the results are practically the same among potential investors, and among people with degree in architecture or civil construction.

Unfortunately, an opportunity to expand the knowledge in these fields is not a factor that would encourage investors to use the proposed solutions.

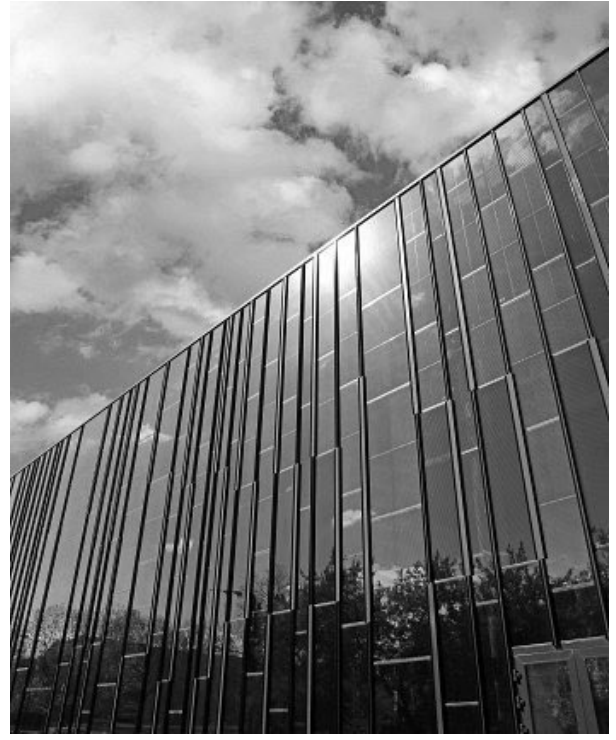

Figure 3: Centre for Sports and Recreation of Medical University of Warsaw photovoltaic modules in a typical facade [5].

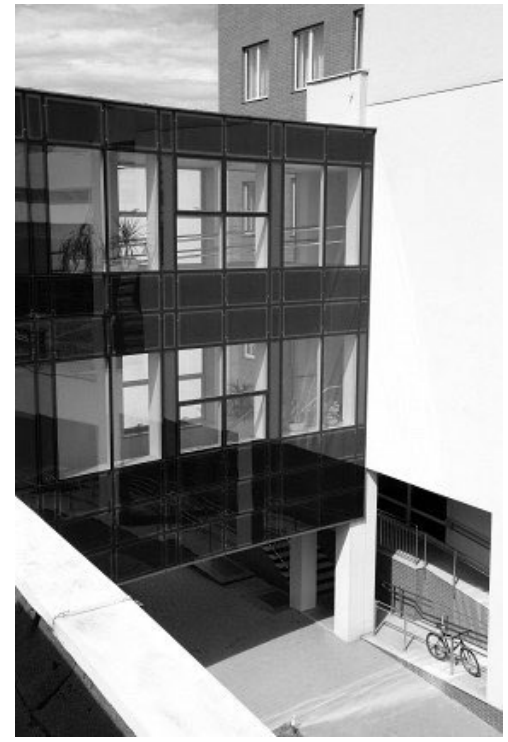

Figure 4: University of Law and Public Administration in Rzeszów photovoltaic modules used in the structural facade [6]. 


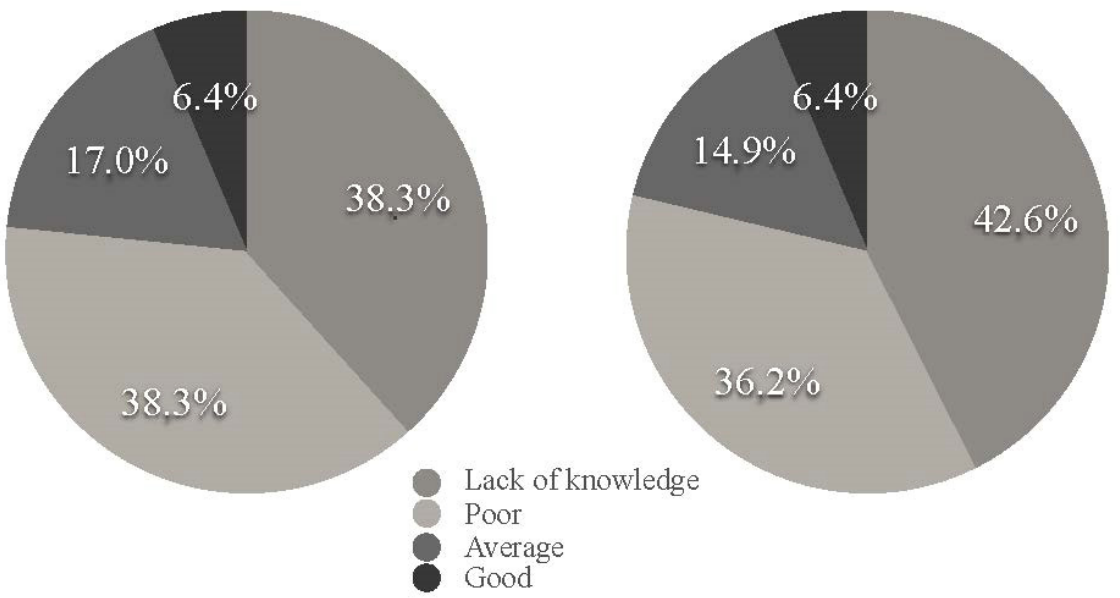

Figure 5: Survey question: "How do you assess your knowledge of legal possibilities of the use of a photovoltaic system?"

Figure 6: Survey question: "How do you assess your knowledge of the possibilities of obtaining funding from the state for PV systems?"
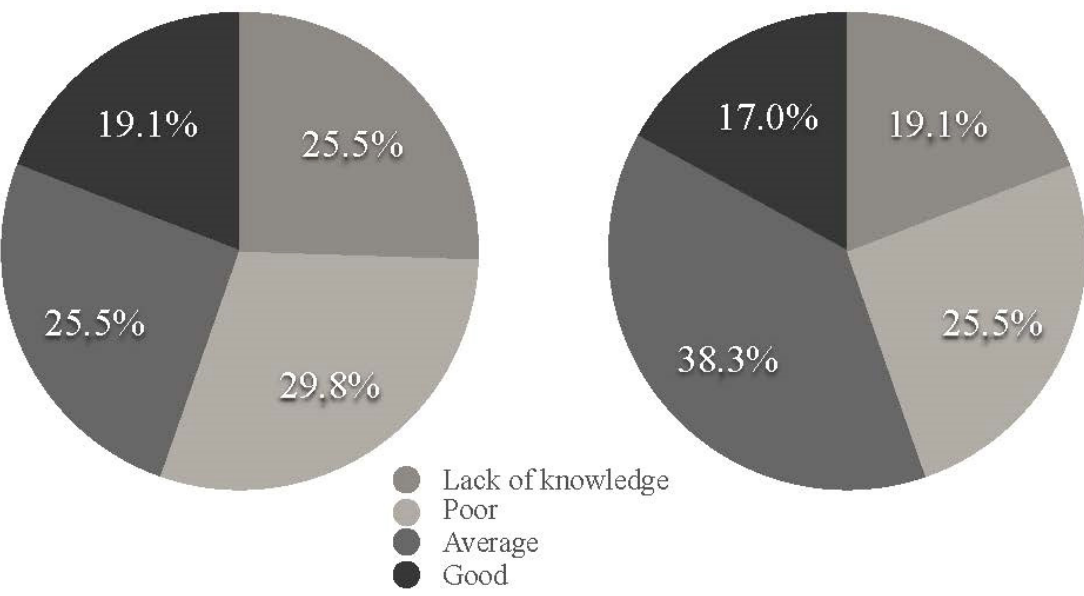

Figure 7: Survey question: "How do you assess your Figure 8: Survey question: knowledge of the technical possibilities of application of photovoltaic systems?" "How do you assess your knowledge of the types of PV systems available to use?" 


\section{Thematic block 2}

The second group of questions concerns the aesthetics of solutions in the field of photovoltaic systems. Their constant development gives a wide range of possibilities for their use. Currently available solutions allow for installation of the PV systems in a form of panels on roofs or facades (as studied by Kim et al. [8]). From an architectural standpoint those solutions are additional design factors, which consistency with the building's architecture and aesthetics can be discussed.

Another possibility are the photovoltaic roof tiles, which are a less invasive solution and blend perfectly with the architecture of the building. Commercially available tiles are produced as classic "plain tiles" in various colors, or simple flat elements, which are much more in harmony with the modern architecture of the building.

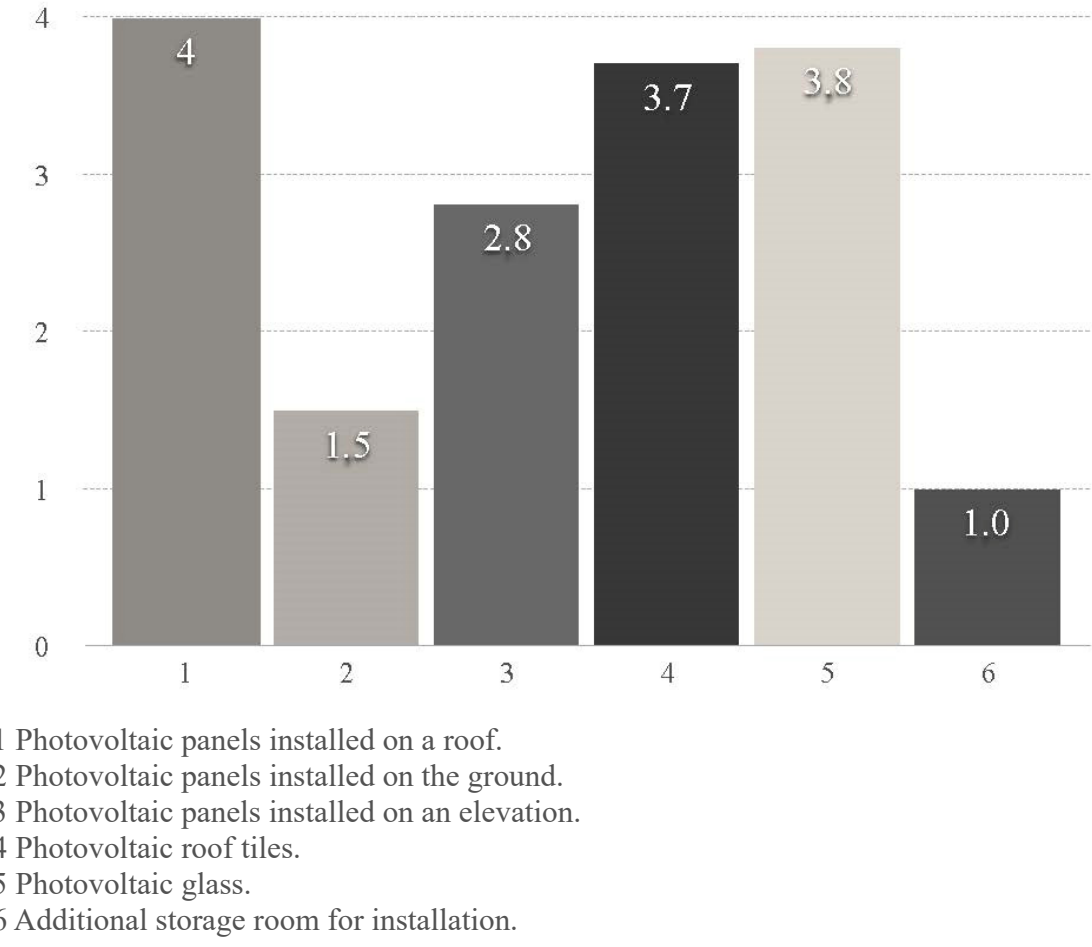

Figure 9: Survey question: "Prioritize the aesthetic preferences of available PV systems, assuming that economic and technical considerations are comparable."

Definitely more interesting ways to apply photovoltaics are the panels that can be integrated with roofs or facades. They create a uniform surface and blend perfectly into the body of the building. When installed on a facade, they can constitute an interesting architectural detail. 
However, in the author's opinion, the solution with the greatest potential is photovoltaic glass. This type of photovoltaic technology allows the investors to benefit from the solar energy in the least invasive manner architecturally. It gives the freedom in shaping a building's body as well as its architectural details. It is an ideal solution for those who recognize the other above mentioned solutions in photovoltaics as aesthetically unsatisfactory. In this case, as claimed by Kaan and Reijeng in their study [9], photovoltaics becomes a building material, rather than an additional element of the building.

In order to evaluate these assumptions were asked questions, which made it possible to collect data regarding the solutions acceptable for potential investors. Photovoltaics turns out to be an affordable option in terms of architecture - the proposed assembly methods have proven to be highly acceptable. Solutions like photovoltaic panels mounted on the roof or photovoltaic roof tiles were highly valued. It should be noted, however, that within those two above mentioned solutions, more highly rated were panels and roof tiles that could blend into building's architecture. The possibility to apply photovoltaic glass was also highly rated.

One can conclude that the author's claim about photovoltaics as a building material, is justified since investors' tastes noticeably gravitate towards less invasive solutions, integrated into the architecture of the building.

\section{Thematic block 3}

The diagnosis of acceptable by investors capital expenditures and additional costs associated with the decision to implement photovoltaic solutions, as well as with its further maintenance, was the subject of the third block.

In office, public and industrial buildings the economic viability and rationality of the above mentioned solutions is justified and most welcome. The energy generated during the day is constantly supplied to the building and completely meets its energetic needs. Assembly costs of the installation and the associated infrastructure in facilities requiring large budgets to be constructed, fade against the total costs. At present, the problem is the ability to use RES solutions in singlefamily housing.

The results show that most investors are hesitant when it comes to implement photovoltaic systems due to budget required for the project, and the total implementation would be possible for them only after receiving support from the state.

The best options for the respondents are a grant of $15 \%$ to $30 \%$ of financing and a preferential bank loan with the financial support of the state (including subsidies covering up to $100 \%$ of costs).

For $29.8 \%$ of respondents, extra budget for the potential use of photovoltaic systems cannot exceed $10 \%$ of the total investment costs, while $21.3 \%$ of respondents would tolerate additional costs in the range of $10 \%$ to $20 \%$ of total investment costs.

At the same time, the costs of installation's maintenance that investors would be able to bear every year, could not exceed 1500 PLN. 
The study also showed that the economic arguments for the use of photovoltaic systems would not be the main factor in the decision to install them.

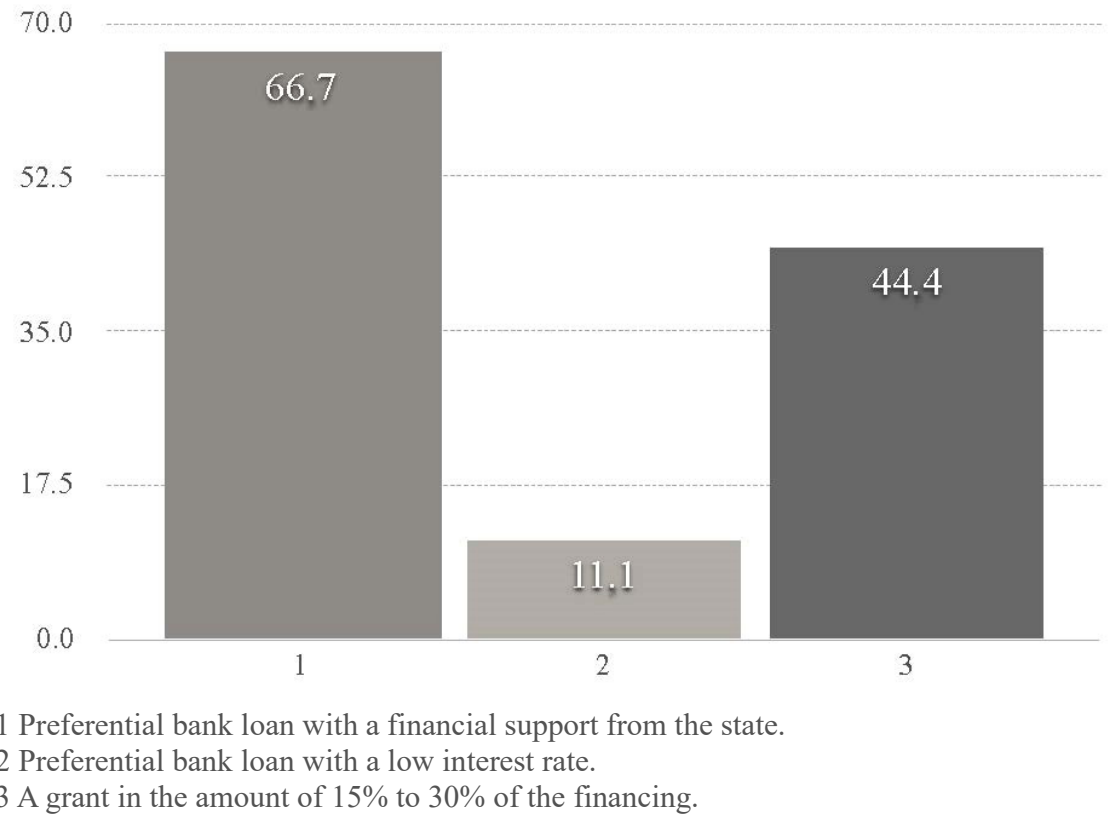

Figure 10: Survey question: "If you were to apply the photovoltaic systems, which economic support option for funding these systems would you prefer?"
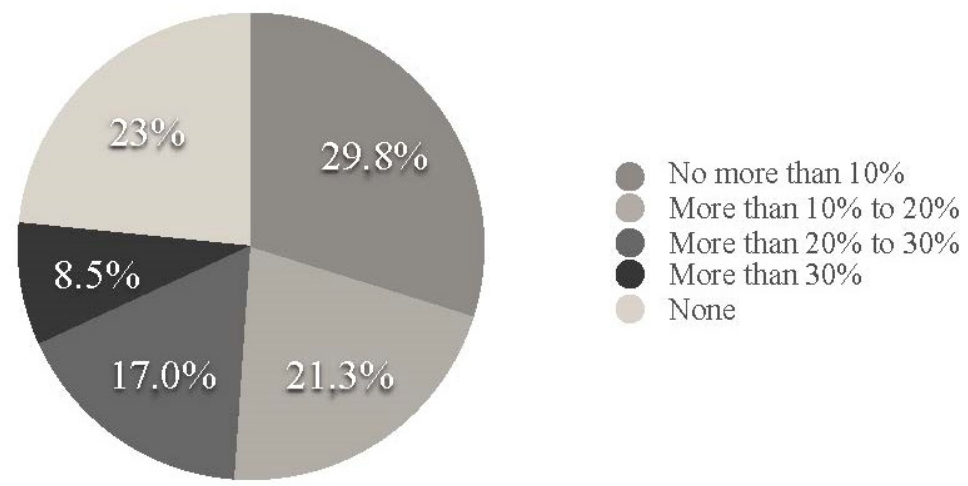

Figure 11: Survey question: "Considering economic aspects, what additional budget would be acceptable for you?"

Technical considerations of the proposed solutions are the most important factors for the respondents, influencing their selection, surpassing the aesthetics of the proposed solutions as well. 


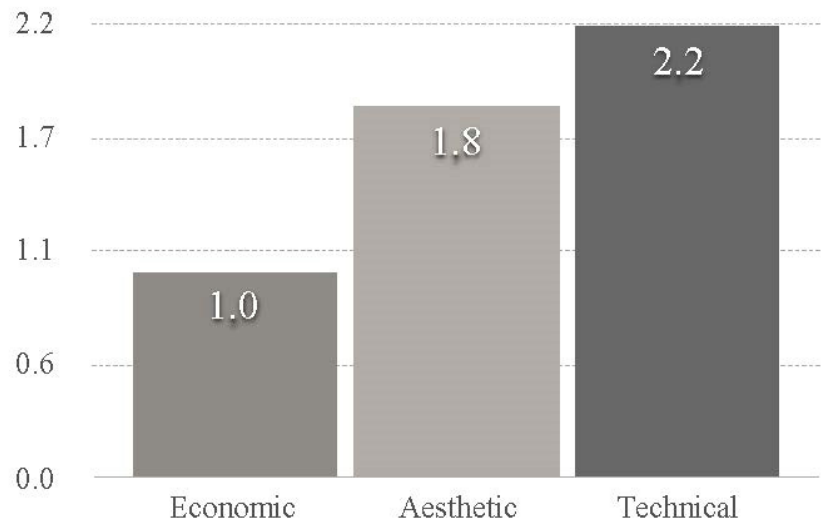

Figure 12: Survey question: "Prioritize considerations you would take into account in choosing a photovoltaic system."

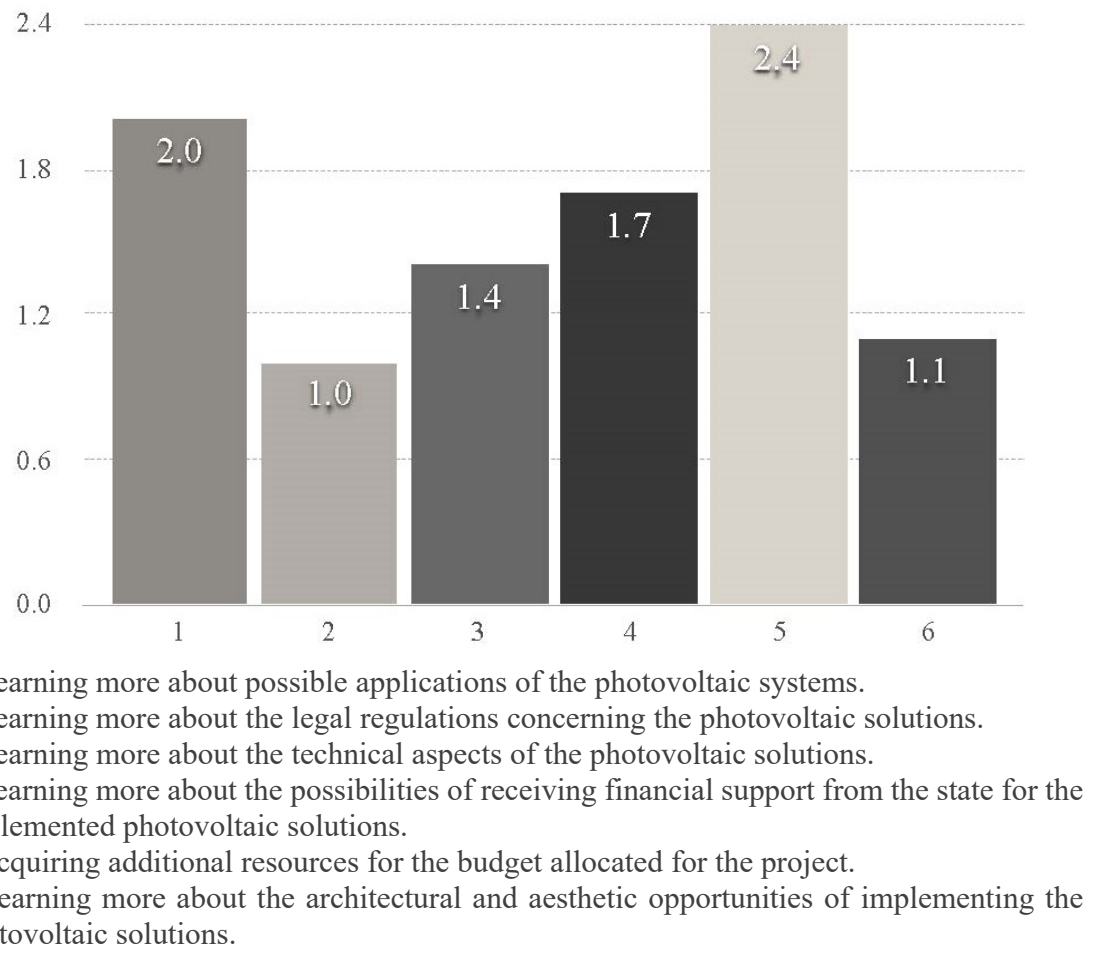

Figure 13: Survey question: "Prioritize the factors that would encourage you to acquire a photovoltaic solution, even if you are not willing to do so at the moment."

An important fact is that an opportunity to acquire additional financial 
resources for the budget allocated for the project is the factor that would most likely entice otherwise undecided investors to implement photovoltaic solutions, surpassing such options as an opportunity to learn more about the possibilities of financial support from the state, or to learn more about the technical aspects of photovoltaic systems or possible applications of those, not to mention architectural and aesthetic aspects of photovoltaic solutions.

\section{Thematic block 4}

The study in the fourth block focused on respondents willing to use photovoltaic systems, and were designed to identify their preferences in the use of the produced energy. Most respondents indicated that the potential receivers, which would be powered by photovoltaic systems, are heating installations (water heater, heat pump, air conditioning, etc.). They were followed by external lighting of buildings and gardens and by internal lighting. Thus were selected receivers characterized by the largest power consumption, though household appliances (refrigerator, washing machine, dishwasher, etc.) and home electronics (including personal computers) were placed very low in the ranking. Together, those receivers also have a high energy consumption.

4

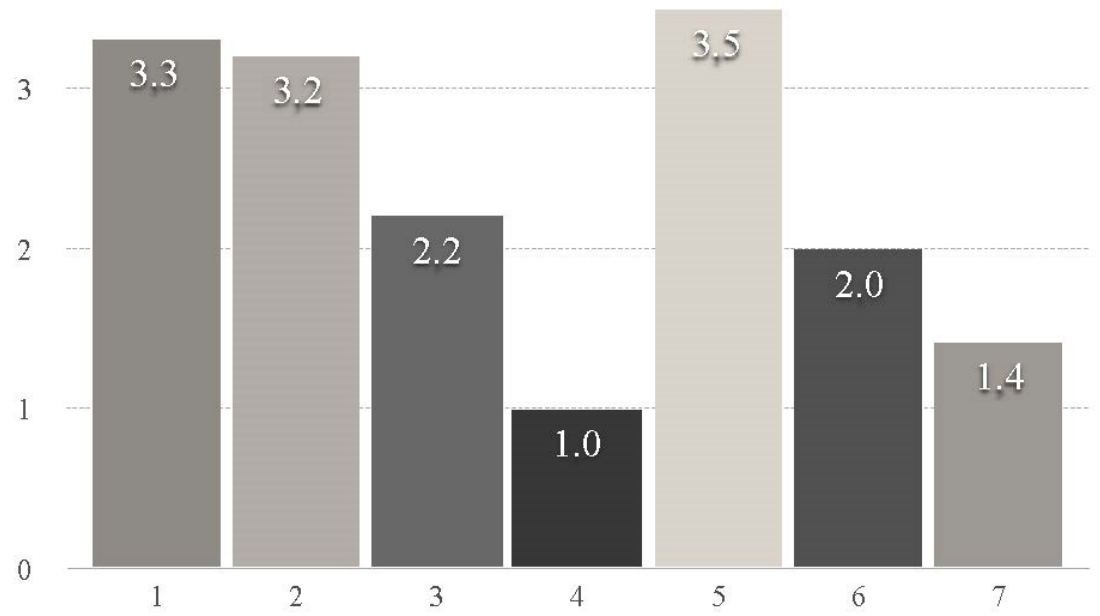

1 Outdoor lighting (building and garden).

2 Internal lighting.

3 Intelligent home control system.

4 Alarm system.

5 Heating installation (water heater, heat pump, air conditioning etc.)

6 Household appliances.

7 Home electronics.

Figure 14: Survey question: "Prioritize the potential receivers you would like to be powered by the energy acquired from photovoltaic systems." 
Also examined were investors' expectations for the percentage of energy from photovoltaic sources in the overall energy balance and in relation to the energy acquired from other renewable energy sources installed in the facility. Analysis of the results showed that $31.9 \%$ of respondents would consider photovoltaic installation a supporting power source (none of the sources cover $100 \%$ of the demand but together they cover more than $100 \%$ ) providing $25 \%$ to $50 \%$ of the energy. $25.5 \%$ of respondents would consider photovoltaic installation a main power source (none of the sources cover $100 \%$ of the demand but together they cover more than $100 \%$ ) providing $50 \%$ to $75 \%$ of the energy.

\section{Conclusions}

The issue that the author makes in the course of her research, which is intended to propagate photovoltaic systems, and in particular photovoltaic glass as a new building material, is to recognize the influence of the energy efficiency and individual RES solutions on the architectural design process as a comprehensive method aimed to resolve a design problem.

The study aimed to determine the economic threshold of accessibility of photovoltaic solutions, specifically the amount of additional costs that the investor is willing to accept, and above all the design possibilities with an emphasis on aesthetic aspects of solutions that are fully accepted by investors.

Results of the study highlight the barriers for a widespread use of photovoltaics in residential construction industry. It is necessary to increase awareness among the communities and among architects and engineers. Presenting the many possibilities of the use of photovoltaic systems in different structures of buildings, along with the development of financial analysis of these solutions seems to be the best move for the dissemination of photovoltaics.

It is essential to define such a state of the designed building, where the PV technology saturation reaches its optimum understood as a resultant of the factors of energy and economic efficiency. It is also important to show potential investors and developers that the currently available means for the implementation of photovoltaic solutions in architecture provide a wide range of formal possibilities and retain a high degree of energy efficiency while obtaining higher quality space.

Basing on the example of the use of photovoltaic glass in single-family housing, which is now one of the leading materials applicable to the theory of sustainable development, the author hypothesizes that, depending on its function, glass can be replaced by a more efficient building material, which is the photovoltaic glass. Analysis of this solution explores the possibilities of its use in many areas.

The results obtained by the author constitute an important part of the research aimed to determine the possibilities to apply particular design procedures in the design process, leading to the implementation of individual RES solutions in the single-family housing.

Sustainable development in architectural design poses many challenges for the industry. Developing - as a result of the research - a model house incorporating RES solutions (the PV glass and cells in its selected structures), as a guideline for new standards in residential construction. Possibilities will be demonstrated 
for the dissemination of the researched materials as typical solutions that are both economically viable and architecturally and aesthetically modern. Finally, it will be proven that glass can be replaced by a more efficient building material, which is the photovoltaic glass.

\section{References}

[1] A. Baranowski, Projektowanie zrównoważone w architekturze, Wydawnictwo Politechniki Gdańskiej, Gdańsk 1998.

[2] http://www.brac-group.co.uk/integrated_solar2.html

[3] http://solarpark.net.pl/projekty-i-wykonanie-farm-naziemnych-orazdachowych/

[4] R. R. King, D. Bhusari, D. Larrabee, X.-Q. Liu, E. Rehder, K. Edmondson, H. Cotal, R. K. Jones, J. H. Ermer, C. M. Fetzer, D. C. Law and N. H. Karam, Solar cell generations over $40 \%$ efficiency, John Wiley \& Sons, Ltd., Prog. Photovolt: Res. Appl. (2012), DOI: 10.1002/pip.1255

[5] http://www.tvs.pl/informacje/zastosowanie-fotowoltaiki-na-fasadachaluminiowych-2014-06-10

[6] http://www.tvs.pl/informacje/zastosowanie-fotowoltaiki-na-fasadachaluminiowych-2014-06- 10/1\#gallery

[7] C.-C. Chen, L. Dou, R. Zhu, C.-H. Chung, T.-B. Song, Y. B. Zheng, S. Hawks, G. Li, P. S. Weiss, and Y. Yang, Visibly Transparent Polymer Solar Cell Produced by Solution Processing, American Chemical Society, ACS Nano, 10.1021/nn3029327

[8] J.-H. Kim, H.-R. Kim, J.-T. Kim, Analysis of Photovoltaic Applications in Zero Energy Building Cases of IEA SHC/EBC Task 40/Annex 52, Sustainability 2015, 7, 8782-8800; doi:10.3390/su7078782

[9] H. Kaan, T. Reijenga, Photovoltaics in an Architectural Context, John Wiley \& Sons, Ltd., Prog. Photovolt: Res. Appl. 2004; 12:395-408 